\title{
INHALED NITRIC OXIDE, RIGHT VENTRICULAR EFFICIENCY, AND PULMONARY VASCULAR MECHANICS: SELECTIVE VASODILATION OF SMALL PULMONARY VESSELS DURING HYPOXIC PULMONARY VASOCONSTRICTION
}

Neal D. Hillman, $\mathrm{MD}^{\mathrm{a}}$

Ira M. Cheifetz, $\mathrm{MD}^{\mathrm{b}}$

Damian M. Craig, $\mathrm{MS}^{\mathrm{a}}$

Peter K. Smith, MD

Ross M. Ungerleider, $\mathrm{MD}^{\mathrm{a}}$

Jon N. Meliones, MD, FCCM ${ }^{\mathrm{b}}$
Objective: In the setting of acute pulmonary artery hypertension, techniques to reduce right ventricular energy requirements may ameliorate cardiac failure and reduce morbidity and mortality. Inhaled nitric oxide, a selective pulmonary vasodilator, may be effective in the treatment of pulmonary artery hypertension, but its effects on cardiopulmonary interactions are poorly understood. Methods: We therefore developed a model of hypoxic pulmonary vasoconstriction that mimics the clinical syndrome of acute pulmonary hypertension. Inhaled nitric oxide was administered in concentrations of 20, 40, and 80 ppm. Results: During hypoxic pulmonary vasoconstriction, the administration of nitric oxide resulted in a significant improvement in pulmonary vascular mechanics and a reduction in right ventricular afterload. These improvements were a result of selective vasodilation of small pulmonary vessels and more efficient blood flow through the pulmonary vascular bed (improved transpulmonary vascular efficiency). The right ventricular total power output diminished during the inhalation of nitric oxide, indicating a reduction in right ventricular energy requirements. The net result of nitric oxide administration was an increase in right ventricular efficiency. Conclusion: These data suggest that nitric oxide may be beneficial to the failing right ventricle by improving pulmonary vascular mechanics and right ventricular efficiency. (J Thorac Cardiovasc Surg 1997;113:1006-13)
A though arterial hypoxia may increase pulmonary vascular resistance, alveolar hypoxia is probably more important in causing hypoxic pulmonary vasoconstriction and acute pulmonary artery hypertension. ${ }^{1}$ Despite an improved understanding of the pathophysiologic features of pulmonary artery hypertension and improvements in diagnosis and supportive care, morbidity and mortality from pulmonary artery hypertension remain high. Pulmonary artery hypertension can lead to an increase in right ventricular ( $R V$ ) afterload and $R V$ energy requirements, which can subsequently result in acute RV

From the Departments of Pediatrics ${ }^{b}$ and Surgery, ${ }^{a}$ Duke University Medical Center, Durham, N.C.

Supported in part by a grant from the Duke Children's Hospital Miracle Network Telethon.

Received for publication August 9, 1996; revisions requested Dec. 5, 1996; revisions received Jan. 14, 1997; accepted for publication Jan. 15, 1997.

Address for reprints: Jon N. Meliones, MD, Duke University Medical Center, Box 3046, Durham, NC 27710.

Copyright (c) 1997 by Mosby-Year Book, Inc.

$0022-5223 / 97 \$ 5.00+0 \quad \mathbf{1 2 / 1 / 8 0 4 0 5}$ failure and reduced oxygen delivery. In these conditions, one approach designed to improve RV performance is to lower RV afterload by decreasing the pulmonary artery pressure. ${ }^{1-3}$ However, intravenous vasodilators directed at reducing the pulmonary artery pressure have been shown to be of limited value. ${ }^{1-3}$ Intravenous vasodilators result in a nonspecific vasodilation that can cause systemic hypotension and a reduction in cardiac function. ${ }^{2,3}$ In contrast to intravenous agents, inhaled nitric oxide (iNO) has been shown to be a selective pulmonary vasodilator. In selected patient populations iNO has been shown to reverse hypoxic pulmonary vasoconstriction while causing minimal systemic effects. ${ }^{4-7}$

Previous investigations of iNO have focused on the ability of iNO to reduce pulmonary artery pressure ${ }^{4-6}$; however, several questions about the administration of iNO remain. The precise location in the pulmonary vasculature where iNO exerts its effects remains uncertain. Discriminating whether iNO results in vasodilation of proximal, large pulmonary vessels or distal, small vessels, or both, is essential in assessing the role of iNO in the various 
causes of pulmonary artery hypertension. Because iNO is delivered to the alveolus, iNO might be more likely to exert its effects by physiologically altering small, distal vessels. Additionally, how does the RV respond to alterations in pulmonary vascular tone as a result of iNO administration? If vasodilation of the pulmonary vasculature is to be clinically significant, it must reduce RV power requirements and increase the efficiency of blood flow through the RV-pulmonary system.

Answers to these questions should help determine which patient populations would benefit from iNO therapy. We hypothesized that (1) iNO administration would improve pulmonary vascular mechanics during hypoxic pulmonary vasoconstriction by vasodilation of distal, small pulmonary vessels, (2) iNO would exert no effects on the proximal, large vessels, and (3) the reduction in RV afterload afforded by iNO would decrease RV total power requirements and increase the efficiency of blood flow through the RV-pulmonary system. The purpose of this study was, therefore, to determine the precise effects of NO during hypoxic pulmonary vasoconstriction on pulmonary vascular mechanics, RV performance, and the efficiency of blood flow through the RVpulmonary system. By understanding where iNO exerts its effects and how iNO alters RV performance one can begin to determine which clinical scenarios would most likely benefit from iNO therapy.

\section{Material and methods}

The surgical procedures and animal care were performed in compliance with the guidelines established by the National Institutes of Health and the Institutional Animal Care and Use Committee of Duke University Medical Center. Fourteen swine $(15$ to $20 \mathrm{~kg})$ were premedicated with acepromazine $(1.1 \mathrm{mg} / \mathrm{kg})$ and ketamine $(22 \mathrm{mg} / \mathrm{kg})$. The trachea of each animal was orotracheally intubated. Mechanical ventilation was initiated with a Siemens SV300 ventilator (Siemens, Solno, Sweden) in the volume control mode. The inspired oxygen fraction $\left(\mathrm{FiO}_{2}\right)$ was set to achieve an arterial oxygen tension $\left(\mathrm{PaO}_{2}\right)$ greater than $60 \mathrm{~mm} \mathrm{Hg}$, and the respiratory rate was adjusted to maintain an arterial carbon dioxide tension $\left(\mathrm{PaCO}_{2}\right)$ between 35 and $45 \mathrm{~mm} \mathrm{Hg}$. Anesthesia was maintained throughout the study with a continuous infusion of fentanyl. Intermittent boluses of pancuronium were used for neuromuscular blockade. To block thromboxane-mediated pulmonary vasoconstriction, the animals were given an initial intravenous bolus of indomethacin $(1.4 \mathrm{mg} / \mathrm{kg})$ with a continuous maintenance infusion $(0.7 \mathrm{mg} / \mathrm{kg}$ per hour $)$. Each animal was heparinized and continuous heparin infusion was begun to prevent clot formation on the intracardiac pressure catheters.
A femoral arterial line was placed to continuously monitor mean arterial pressure and to obtain arterial blood gas samples. After a median sternotomy, the pericardium was incised and fashioned into a pericardial cradle. An ultrasonic flow probe (Transonic Systems Inc., Ithaca, N.Y.) was placed around the pulmonary artery at the level of the RV outflow tract to measure cardiac output. Micromanometer strain gauge pressure catheters (Millar Instruments Inc., Houston, Tex.) were introduced through subcutaneously tunneled sheaths and placed in the pulmonary artery (at the level of the flow probe), RV, and left atrium. A fourth pressure catheter was placed into an introducer sheath and positioned in the thoracic cavity at the level of the left atrium. A chest tube was positioned in the thoracic cavity, and atrial pacing wires were inserted. A fluid-filled pouch was positioned at the level of the right atrium-superior vena cava junction and connected to a roller pump. This maintained continuous cooling of the sinoatrial node to suppress episodes of tachycardia. The chest and skin were then closed, all air leaks sealed, and the chest tube placed to water seal. The ventilatory rate was adjusted to maintain a $\mathrm{PaCO}_{2}$ value of 35 to $45 \mathrm{~mm} \mathrm{Hg}$. A positive end-expiratory pressure of 3 $\mathrm{cm} \mathrm{H}_{2} \mathrm{O}$ was added to prevent alveolar collapse. These ventilatory parameters were held constant throughout the study.

Hypoxic pulmonary vasoconstriction. A baseline data set was obtained before global hypoxia was induced. Global hypoxic pulmonary vasoconstriction was produced by administration of an inhaled hypoxic gas mixture. The hypoxic gas mixture was obtained by blending nitrogen

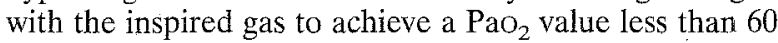
$\mathrm{mm} \mathrm{Hg}\left(\mathrm{FiO}_{2} 16 \%\right.$ to $\left.18 \%\right)$ and was titrated to achieve a $50 \%$ increase in mean pulmonary artery pressure. The gas mixture was maintained constant throughout the remainder of the study period. After the development of hypoxic pulmonary vasoconstriction, the animal's condition was allowed to stabilize for 30 minutes. To eliminate heart rate effects on calculations of pulmonary impedance and RV power indices, the hearts were atrially paced at 150 beats/min during data acquisition.

After the development of hypoxic pulmonary vasoconstriction, a second data set was obtained. NO (NO 777 ppm and $\mathrm{NO}_{2}<0.1 \mathrm{ppm}$, National Specialty Gases, Durham, N.C.) was then continuously blended into the inspiratory circuit of the ventilator. The gas mixture was withdrawn from the inspiratory circuit at the level of the endotracheal tube, and NO levels calculated by chemiluminescent analysis (model $42 \mathrm{H}$, Thermo Environmental Instruments Inc., Franklin, Mass.). The NO concentration was then increased in a nonrandomized sequential fashion from $20 \mathrm{ppm}$ to $40 \mathrm{ppm}$ to $80 \mathrm{ppm}$. The support conditions were returned to baseline and measurements repeated. At each incremental change of NO the animal's condition was permitted to stabilize for 20 minutes before data acquisition.

Measurements and data analysis. Each data set consisted of 50 seconds of pressure and flow waveforms sampled at $500 \mathrm{~Hz}$. Direct measurements included systemic blood pressure, RV pressure, pulmonary artery pressure, left atrial pressure, intrathoracic cavity pressure, tracheal pressure, and pulmonary artery blood flow. $\mathrm{Ar}$ - 
Table I. Cardiopulmonary measurements before and during hypoxia

\begin{tabular}{lccccccc} 
& $\begin{array}{c}\mathrm{PaO}_{2} \\
(\mathrm{~mm} \mathrm{Hg})^{*}\end{array}$ & $\begin{array}{c}\mathrm{Ppa} \\
(\mathrm{mm} \mathrm{Hg})^{*}\end{array}$ & $\begin{array}{c}\mathrm{CO} \\
(\mathrm{mllmin})^{*}\end{array}$ & $\begin{array}{c}\text { Rin } \\
\left(\text { dyne } \cdot \mathrm{sec} / \mathrm{cm}^{5}\right)^{*}\end{array}$ & $\begin{array}{c}\mathrm{TVE} \\
(\mathrm{L} / \mathrm{W}-\mathrm{min})^{*}\end{array}$ & $\begin{array}{c}\mathrm{TP} \\
(\mathrm{mW})^{*}\end{array}$ & $\begin{array}{c}\mathrm{RV} \mathrm{dP} / \mathrm{dt} \\
(\mathrm{mm} \mathrm{Hg} / \mathrm{sec})^{*}\end{array}$ \\
\hline Normoxia & $86.0 \pm 2.0$ & $15.4 \pm 1.3$ & $1313 \pm 86$ & $1034 \pm 109$ & $25.0 \pm 0.2$ & $52.6 \pm 4.9$ & $418 \pm 23$ \\
Hypoxia & $50.9 \pm 1.7$ & $22.8 \pm 1.6$ & $1276 \pm 68$ & $1530 \pm 154$ & $17.9 \pm 1.2$ & $72.5 \pm 5.8$ & $582 \pm 57$ \\
\hline
\end{tabular}

$P p a$, Pulmonary artery pressure; $C O$, cardiac output; Rin, pulmonary input resistance; TVE, transpulmonary vascular efficiency; $T P, \mathrm{RV}$ total power. ${ }^{*} p<0.05$ versus normal lung.

terial blood gas measurements were obtained at each measurement period. $\mathrm{PaO}_{2} / \mathrm{FiO}_{2}$ ratios and oxygen delivery (cardiac output $\times$ [hemoglobin $\times$ arterial $\mathrm{O}_{2}$ saturation $\left.\times 1.34]+\left[\mathrm{PaO}_{2} \times 0.003\right]\right)$ were calculated.

Pulmonary vascular mechanics and RV performance. In addition to pulmonary artery pressure, pulmonary measurements included pulmonary input resistance (mean pulmonary artery pressure/mean pulmonary blood flow) and pulmonary impedance. To calculate the impedance spectrum, the data sets were individually separated into cardiac cycles, and the waveforms were averaged. Characteristic impedance, which has been shown to evaluate the large vessels of the proximal pulmonary vascular bed ${ }^{8}$ was then derived from the impedance spectrum as described later. In contrast, pulmonary input resistance evaluates the entire pulmonary vasculature (proximal and distal vessels). ${ }^{8}$ To evaluate the effects of iNO on the proximal vessels, characteristic impedance was examined. To evaluate the distal small vessels, we compared the changes that occurred in characteristic impedance with those that occurred in pulmonary input resistance. For example, if iNO administration results in a reduction in input resistance with no change in characteristic impedance, then the reduction in input resistance is related to alterations in distal small vessels and not proximal large vessels.

RV performance was evaluated by calculating $R V$ total power, transpulmonary vascular efficiency, and maximal $\mathrm{RV}$ rate of pressure rise $(\mathrm{dP} / \mathrm{dt})$. $\mathrm{RV}$ total power was obtained from the impedance and flow magnitudes at all frequencies (impedance spectrum $\times$ pulmonary artery blood flow squared) and differentiated into components of steady power (energy required to move blood forward) and oscillatory power (energy wasted to accelerate blood in a pulsatile fashion). Maximal $\mathrm{RV} \mathrm{dP} / \mathrm{dt}$ measured by the RV pressure catheter was recorded as an index of RV chamber contractility. Because this has been shown to be sensitive to afterload, the simultaneous measurement of pulmonary artery pressure was used to interpret this index. The final measure of $\mathrm{RV}$ performance was transpulmonary vascular efficiency, an index we have developed in an attempt to quantify the complex relationship between RV power and pulmonary blood flow. ${ }^{9-12}$ Transpulmonary vascular efficiency was calculated by dividing pulmonary blood flow by the power required to produce this flow (pulmonary artery blood flow/RV total power).

Baseline hypoxic pulmonary vasoconstriction parameters were compared between each level of NO administration with a two-way analysis of variance for repeated measures. Prehypoxia and posthypoxia values were compared in a similar manner. A value of $p<0.05$ was considered significant. Measurements are reported as mean values plus or minus the standard error of the mean.

\section{Results}

Effects of hypoxic pulmonary vasoconstriction on cardiopulmonary interactions. Results from the 14 animals under conditions of normoxia and global hypoxia are summarized in Table I. Animals were maintained at an $\mathrm{Fio}_{2}$ between 0.16 and 0.18 to achieve hypoxic conditions and pulmonary artery hypertension. Mean pulmonary artery pressures increased by $48 \%(15.4 \pm 1.3$ vs $22.8 \pm 1.6 \mathrm{~mm} \mathrm{Hg}$, $p=0.00003$ ) during hypoxia (Table 1). Hypoxic conditions resulted in a $48 \%$ increase in pulmonary input resistance $(1034 \pm 109$ vs $1530 \pm 154$ dyne $\left.\cdot \mathrm{sec} / \mathrm{cm}^{5}, p=0.004\right)$. After the initiation of hypoxia, the total power output of the RV increased by $37 \%(52.6 \pm 4.9$ vs $72.5 \pm 5.8 \mathrm{~mW}, p=0.006)$. There was a significant increase in maximal $\mathrm{RV}$ $\mathrm{dP} / \mathrm{dt}(418 \pm 23$ vs $582 \pm 57 \mathrm{~mm} \mathrm{Hg} / \mathrm{sec}, p=0.01)$. Transpulmonary vascular efficiency decreased by $28 \%$ during hypoxic pulmonary vasoconstriction $(25.0 \pm 1.1$ vs $17.9 \pm 1.2 \mathrm{~L} / \mathrm{W}$-min, $p=0.005)$, which demonstrated less efficient blood flow through the RV-pulmonary circuit. During inhalation of the hypoxic gas mixture the $\mathrm{PaO}_{2}$ value decreased $(86.0 \pm 2.0$ vs $50.9 \pm 1.7 \mathrm{~mm} \mathrm{Hg}, p=0.00002)$ by design.

Effect of iNO on gas exchange. The effects of NO on cardiopulmonary measurements are summarized in Table II. There was no change in arterial oxygen saturation or $\mathrm{PaO}_{2}$ during inhalation of NO. This was as expected inasmuch as a hypoxic gas mixture decreases the alveolar $\mathrm{Po}_{2}$ and decreases the amount of oxygen available for gas exchange. During the study period there was no significant change in $\mathrm{PaCO}_{2}$.

Effect of iNO on pulmonary vascular mechanics and $R V$ performance. Characteristic impedance remained constant with the administration of $20 \mathrm{ppm}$ of iNO and did not change with increased iNO concentrations, which indicated no change in the compliance or cross-sectional area of the large 
The Joumal of Thoracic and

Cardiovascular Surgery

Hillman et al.

1009

Volume 113, Number 6

Table II. Cardiorespiratory measurements during NO administration

\begin{tabular}{lccccc}
\hline & $0 \mathrm{ppm}$ & $20 \mathrm{ppm}$ & $40 \mathrm{ppm}$ & $80 \mathrm{ppm}$ & $0 \mathrm{ppm}$ \\
\hline $\mathrm{Ppa}(\mathrm{mm} \mathrm{Hg})$ & $22.8 \pm 1.0$ & $19.8 \pm 1.3^{*}$ & $18.9 \pm 1.0^{*}$ & $18.3 \pm 0.9^{*}$ & $23.1 \pm 1.2$ \\
$\mathrm{CO}(\mathrm{ml} / \mathrm{min})$ & $1276.8 \pm 67.7$ & $1369.1 \pm 87.4$ & $1391.6 \pm 65.6$ & $1357.7 \pm 67.7$ & $1266.4 \pm 68.9$ \\
$\mathrm{Rin}\left(\mathrm{dyne} \cdot \mathrm{sec} / \mathrm{cm}^{5}\right)$ & $1530.7 \pm 154.2$ & $1230.1 \pm 100.8^{*}$ & $1173.9 \pm 92.1^{*}$ & $1171.2 \pm 95.4^{*}$ & $1538.6 \pm 124.5$ \\
$\mathrm{Zo}\left(\mathrm{dyne} \cdot \mathrm{sec} / \mathrm{cm}^{5}\right)$ & $149.7 \pm 8.7$ & $139.2 \pm 9.3$ & $141.3 \pm 8.5$ & $145.0 \pm 9.5$ & $151.3 \pm 8.8$ \\
$\mathrm{TP}(\mathrm{mW})$ & $72.5 \pm 5.8$ & $71.2 \pm 6.9$ & $67.5 \pm 4.8^{*}$ & $64.6 \pm 4.6^{*}$ & $71.9 \pm 5.3$ \\
$\mathrm{SP}(\mathrm{mW})$ & $64.0 \pm 4.6$ & $60.7 \pm 5.9$ & $57.7 \pm 3.9^{*}$ & $54.3 \pm 3.8^{*}$ & $63.7 \pm 4.7$ \\
$\mathrm{OP}(\mathrm{mW})$ & $8.5 \pm 1.4$ & $10.5 \pm 1.8$ & $9.9 \pm 1.5$ & $10.2 \pm 1.5$ & $8.2 \pm 1.5$ \\
$\% \mathrm{SP}$ & $88.7 \pm 1.0$ & $85.4 \pm 1.7$ & $87.1 \pm 2.2$ & $85.8 \pm 2.1$ & $88.6 \pm 1.8$ \\
$\% \mathrm{OP}$ & $11.3 \pm 1.0$ & $14.6 \pm 1.7$ & $14.8 \pm 1.9$ & $16.9 \pm 1.9$ & $11.4 \pm 1.8$ \\
$\mathrm{TVE}(\mathrm{L} / \mathrm{W}-\mathrm{min})$ & $17.4 \pm 1.3$ & $19.4 \pm 1.2^{*}$ & $20.6 \pm 1.2^{*}$ & $21.1 \pm 1.2^{*}$ & $17.6 \pm 1.2$ \\
$\mathrm{RV} \mathrm{EDP}(\mathrm{mm} \mathrm{Hg})$ & $3.9 \pm 0.7$ & $3.9 \pm 0.5$ & $4.1 \pm 0.5$ & $4.2 \pm 0.4$ & $4.0 \pm 0.7$ \\
$\mathrm{RV} \mathrm{dP/dt} \mathrm{(mm} \mathrm{Hg/sec)}$ & $581.7 \pm 56.6$ & $620.2 \pm 76.5$ & $603.1 \pm 88.2$ & $589.9 \pm 68.8$ & $583.3 \pm 61.3$ \\
$\mathrm{MAP}(\mathrm{mm} \mathrm{Hg})$ & $50.9 \pm 4.0$ & $58.9 \pm 4.6$ & $54.3 \pm 4.6$ & $54.1 \pm 4.7$ & $52.2 \pm 2.4$ \\
$\mathrm{PaO}_{2}$ (torr) & $50.9 \pm 1.7$ & $49.3 \pm 2.9$ & $49.6 \pm 2.6$ & $49.3 \pm 2.7$ & $48.8 \pm 4.5$ \\
$\mathrm{DO}_{2}(\mathrm{dl} / \mathrm{min})$ & $145.3 \pm 8.4$ & $151.6 \pm 11.7$ & $154.1 \pm 7.8$ & $149.2 \pm 6.6$ & $147.7 \pm 7.6$ \\
\hline
\end{tabular}

$P p a$, Pulmonary artery pressure; $C O$, cardiac output; Rin, pulmonary input resistance; $Z o$, characteristic impedance; $T P, \mathrm{RV}$ total power; $S P, \mathrm{RV}$ steady power; $O P$, RV oscillatory power; $T V E$, transpulmonary vascular efficiency; $E D P$, end-diastolic pressure; $M A P$, mean arterial pressure; $D \mathrm{O}_{2}$, oxygen delivery. ${ }^{*} p<0.05$ versus 0 ppm.

pulmonary vessels. During administration of iNO at $20 \mathrm{ppm}$, pulmonary artery pressure fell by $13 \%$ (Table II, Fig. 1). With each incremental increase in iNO concentration pulmonary artery pressure was further reduced, and the maximal decrease of $20 \%$ occurred at $80 \mathrm{ppm}$. However, there were no statistically significant differences when the various concentrations of iNO were compared. Pulmonary input resistance fell by $20 \%$ during administration of $20 \mathrm{ppm}$ of NO. The greatest reduction of input resistance, $24 \%$, was noted at 40 and $80 \mathrm{ppm}$.

Total power generated by the RV decreased during iNO administration with a reduction of $11 \%$ at $80 \mathrm{ppm}$ (Table II, Fig. 2). The components of total power include steady and oscillatory power. The steady power, or energy produced by the RV to move the blood forward, continually diminished with each increase in NO concentration, with a $16 \%$ decrease at $80 \mathrm{ppm}$. There was no significant change in the absolute value of oscillatory power (wasted energy to oscillate the blood vessels and energy required to overcome inertia). iNO administration resulted in a $21 \%$ increase in transpulmonary vascular efficiency at $80 \mathrm{ppm}$, indicating more efficient blood flow through the RV-pulmonary circuit (Fig. 3). Preload, as measured by RV end-diastolic pressure, did not change significantly throughout the study $(3.9 \pm 0.7$ vs $3.9 \pm 0.5 \mathrm{~mm} \mathrm{Hg}, p=0.83)$. There was no significant change in maximal $\mathrm{dP} / \mathrm{dt}$, an indicator of myocardial contractility.

Effect of iNO on systemic circulation and oxygen delivery. Systemic pressures did not change significantly at any level of NO concentration studied.
Because of the study design, there was no significant improvement in arterial oxygenation. However, there was a trend toward an increase in oxygen delivery that was greatest at $40 \mathrm{ppm}(145.3 \pm 8.4$ vs $154.1 \pm 7.8 \mathrm{dl} / \mathrm{min})$, but this did not reach statistical significance.

\section{Discussion}

Despite improvements in medical support for patients with global hypoxic pulmonary vasoconstriction, RV dysfunction continues to be responsible for increased morbidity and mortality. Global hypoxic pulmonary vasoconstriction is associated with an acute elevation of pulmonary artery pressure and a decrease in RV performance. The increase in $R V$ total power requirements can result in $\mathrm{RV}$ dysfunction and subsequent cardiac failure. ${ }^{1} \mathrm{~A}$ reduction in RV afterload might improve RV performance and reduce the likelihood of RV dysfunction. ${ }^{13}$ The use of intravenous vasodilators to treat hypoxic pulmonary vasoconstriction is limited because of the severe systemic vasodilation, worsening cardiac performance, and diminished ventilationperfusion matching that result. ${ }^{2,3}$ Because iNO selectively reduces pulmonary artery pressure, iNO administration might provide an important therapeutic strategy for patients with hypoxic pulmonary vasoconstriction. ${ }^{1-3}$

In this study, iNO administration reduced pulmonary artery pressure by $20 \%$ and pulmonary input resistance by $24 \%$. These effects resulted in a significant reduction in $\mathrm{RV}$ total power requirements, an increase in transpulmonary vascular efficiency, and 


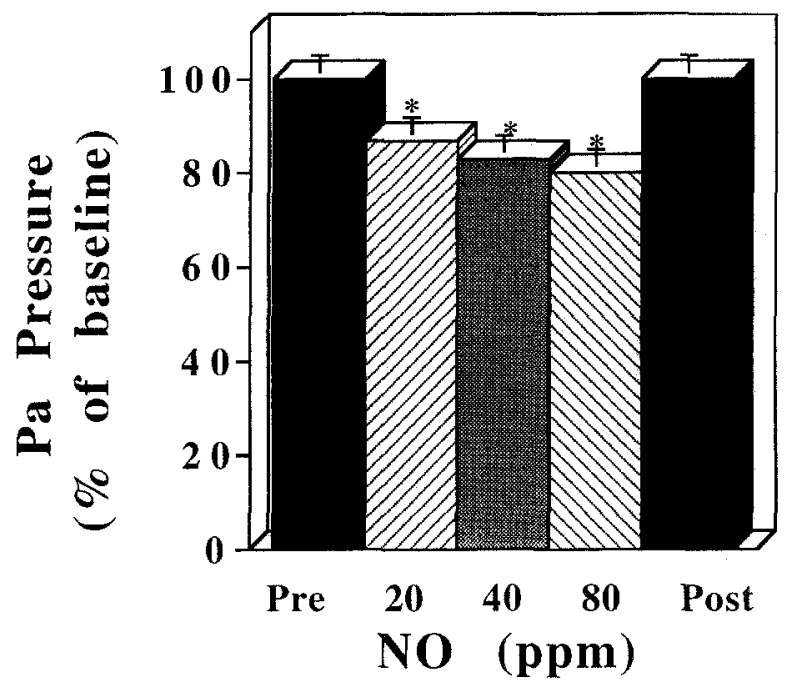

Fig. 1. NO resulted in a decrease of pulmonary artery (Pa) pressure. * $p<0.05$ versus 0 ppm. Pre, Before NO; Post, after NO.

improvement in RV performance. One objective of this study was to define more precisely the effects of iNO on the pulmonary vasculature. Conventional cardiopulmonary physiology is based on "steadyflow" hemodynamics. Because pulmonary blood flow is pulsatile, conventional steady-flow measurements do not fully describe cardiopulmonary hemodynamics. ${ }^{14}$ Fourier analysis of pulmonary pressure and blood flow separates these measurements into steady and pulsatile components, which permits quantitative descriptions regarding the physical state of the pulmonary vasculature. ${ }^{15}$ In contrast to pulmonary input resistance, which describes only steady-state pressure and flow, characteristic impedance includes the pulsatile components of blood flow in the pulmonary vascular bed. Characteristic impedance calculated from the impedance spectrum defines the physical state of the pulmonary vascular bed. Characteristic impedance varies inversely to the compliance and the cross-sectional area of the large pulmonary vessels. As has been demonstrated by our data and by others, iNO results in a significant reduction in input resistance. ${ }^{6,7}$ However, in our study, characteristic impedance remained constant. This demonstrated that the vasodilator properties of iNO were effective at the level of the small pulmonary vessels with a minimal effect on larger pulmonary vessels. Similar results were suggested by Celermajer and associates ${ }^{16}$ in children with obstructive lesions of the left side of the heart. Segmental arterial diameter was unchanged during in-

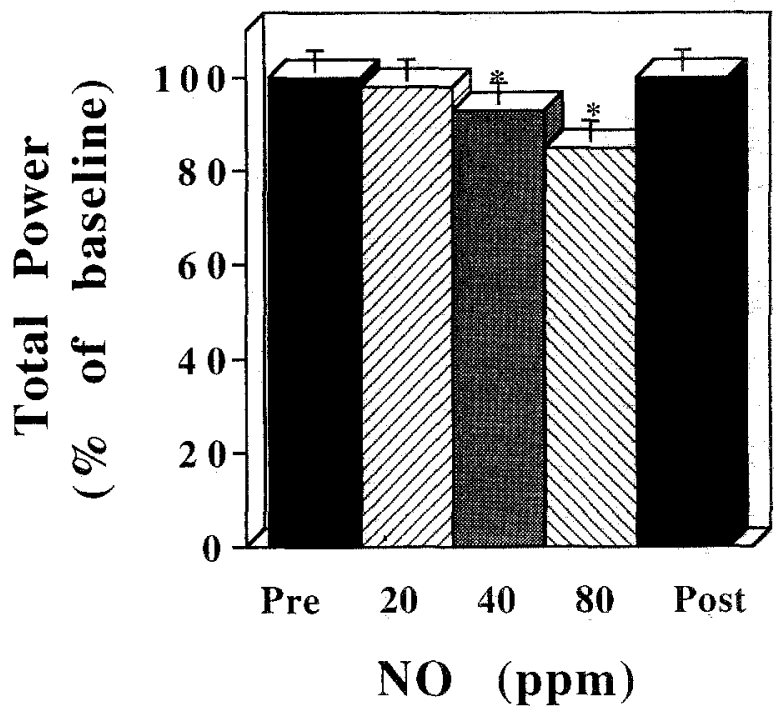

Fig. 2. Total RV power output diminished during NO administration and reached significance at $80 \mathrm{ppm}$. ${ }^{*} p<$ 0.05 versus 0 ppm. Pre, Before NO; Post, after NO.

fusion of $\mathrm{N}^{\mathrm{g}}$-monomethyl-L-arginine (an inhibitor of NO synthesis), suggesting the effect of iNO was distal to the segmental pulmonary arteries. Similarly in our model iNO resulted in relaxation of smooth muscle cells that were in close proximity to the alveoli with no evidence of vasodilation of the larger proximal vessels. These data may be helpful in defining which pathophysiologic conditions will respond to iNO therapy. By identifying the precise location where iNO acts, one can begin to understand why patients with certain pathophysiologic conditions benefit from iNO administration whereas others do not. Patients with primarily small-vessel abnormalities (pulmonary venous hypertension as occurs in mitral stenosis, neonates with pulmonary artery hypertension, and patients with acute respiratory distress syndrome) may respond favorably to iNO. In these patients, attempts to use iNO to dilate small distal vessels may prove beneficial. In contrast, patients with a predominant arteriolar abnormality, such as occurs in certain patients with primary pulmonary artery hypertension, may not show a response to iNO. Further clinical studies appear warranted. In these clinical studies, separation of patients in whom the pulmonary artery hypertension is based on small-vessel abnormalities from those with large-vessel abnormalities may provide greater insight into the clinical utility of iNO.

RV performance was evaluated by several traditional measurements including cardiac output, RV 
end-diastolic pressure, and maximal $\mathrm{RV} \mathrm{dP} / \mathrm{dt}$. Because these approaches provide a limited evaluation of the RV, we measured RV total power output and transpulmonary vascular efficiency. RV total hydraulic power is calculated from the impedance spectrum and differentiated into components of steady power (energy required to move blood forward) and oscillatory power (wasted energy to move blood in an oscillatory fashion). Increased total power results in greater RV energy requirements. This is in contrast to RV work, which examines the load on the RV alone without regard to time. For example, walking up a flight of stairs requires the same amount of work as running up the same stairs. However, the power output is higher for running versus walking because the same amount of work is performed in a shorter period. Similarly, a heart that is producing a set amount of work per beat at a slow heart rate is generating less power than one producing the same work per beat at a high heart rate. By evaluating RV total power one can measure the energy required to achieve a given pulmonary blood flow. An increase in RV total power may result from an increase in $\mathrm{RV}$ work or a decrease in the time required to perform the work. Provided pulmonary blood flow does not change, a decrease in RV total power is beneficial because it indicates a decrease in the energy required by the RV to produce the given pulmonary blood flow.

Transpulmonary vascular efficiency couples RV workload with pulmonary blood flow and describes how efficiently blood flows through the RV-pulmonary circuit. Conditions that decrease pulmonary blood flow and increase RV total power requirements result in a reduction in transpulmonary vascular efficiency. Therefore, by linking power and output, transpulmonary vascular efficiency is a measure of RV performance and might indicate trends in $\mathrm{RV}$ performance not appreciated when power and output are evaluated separately. ${ }^{9}$ Transpulmonary vascular efficiency has been shown to be sensitive to small changes in RV performance. ${ }^{9-11}$ Transpulmonary vascular efficiency links the amount of pulmonary blood flow with the RV power requirements necessary to produce this blood flow, providing a more precise evaluation of the RVpulmonary system. An increase in transpulmonary vascular efficiency indicates a higher flow for a given amount of RV power output and, therefore, a more efficient RV-pulmonary system. In contrast, a fall in transpulmonary vascular efficiency indicates less pulmonary blood flow for a given RV power output

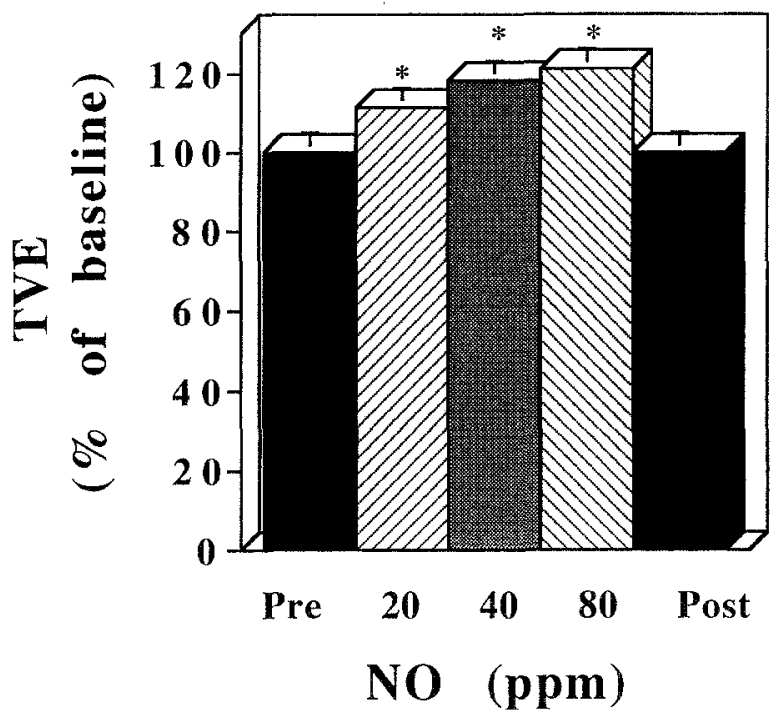

Fig. 3. NO administration significantly improved transpulmonary vascular efficiency (TVE) (pulmonary blood flow/total RV power). * $p<0.05$ versus 0 ppm. Pre, Before NO; Post, after NO.

and a fall in efficiency. Transpulmonary vascular efficiency has been shown to be a sensitive indicator of overall effectiveness of the RV-pulmonary system. ${ }^{9-11}$

When hypoxic pulmonary vasoconstriction was created by global hypoxia, RV power increased by $37 \%$ and pulmonary blood flow decreased. There was a corresponding decrease in transpulmonary vascular efficiency by $24 \%$, indicating less efficient blood flow through the pulmonary vessels. When iNO was administered during hypoxic pulmonary vasoconstriction, total RV power and steady power decreased. The reduction in $\mathrm{RV}$ power requirements should be beneficial to the RV by decreasing $\mathrm{RV}$ myocardial oxygen demand. iNO administration also resulted in a $24 \%$ increase in transpulmonary vascular efficiency as pulmonary blood flow became more efficient. Of note is that transpulmonary vascular efficiency significantly increased at low doses of $\mathrm{iNO}$ before a significant reduction in $\mathrm{RV}$ power. It was not until a $40 \mathrm{ppm}$ concentration of iNO was administered that RV power significantly decreased. Thus transpulmonary vascular efficiency is a sensitive indicator of RV performance as has been suggested in previous studies. ${ }^{9-11}$ One objective of iNO therapy is to improve RV performance by improving pulmonary vascular mechanics. Our data suggest that in this model of hypoxic pulmonary 
vasoconstriction, iNO achieves this goal and is beneficial for the RV.

The effects of iNO may be more dramatic in conditions in which preexisting RV dysfunction is present. The dysfunctional RV is sensitive to even small changes in pulmonary vascular resistance or impedance. Our study was an acute model and as such the RV was not subject to stress for a long period. In clinical conditions in which the RV is subjected to stress for a longer period, RV performance might progressively deteriorate. Our data might, therefore, underestimate the clinical benefit of iNO on RV performance.

The effect of iNO on left ventricular filling pressures has been examined in a few clinical studies. ${ }^{12,17,18}$ In these studies there was an increase in pulmonary capillary pressure. In theory, this might be a result of increased left ventricular volume as a result of an increase in RV output. Although the increase in left ventricular volume may be beneficial in conditions in which left ventricular volume is limited, it may prove detrimental in conditions in which left ventricular volume is excessive. Such conditions include those in patients with congestive left ventricular dysfunction. In these conditions, iNO should be used cautiously and the effects of iNO on left ventricular performance monitored.

There was a trend toward dose-dependent changes associated with iNO; however, these changes did not reach significance. The effective dose of iNO may vary depending on the pathophysiologic conditions. In several studies that examined the use of iNO in acute respiratory distress syndrome, doses as low as 2 to $3 \mathrm{ppm}$ achieved beneficial results. ${ }^{19-21}$ After operations for congenital heart disease, iNO doses required to produce the desired results ranged from $2 \mathrm{ppm}$ to 80 ppm. ${ }^{6-7,22-24}$ These studies indicate that the dose of iNO must be individualized for each patient and titrated to the lowest dose that achieves the desired effects.

We observed no significant change in the $\mathrm{PaO}_{2} /$ $\mathrm{FiO}_{2}$ ratio during the administration of iNO. The decreased level of alveolar $\mathrm{Po}_{2}$ in this model limited the amount of oxygen available for gas exchange and would not permit an increase in the $\mathrm{PaO}_{2} / \mathrm{FiO}_{2}$ ratio. Frostell and coworkers ${ }^{5}$ noted similar findings in healthy adult human volunteers breathing a hypoxic gas mixture. In that study, despite a constant $\mathrm{PaO}_{2} /$ $\mathrm{FiO}_{2}$ ratio and no improvement in $\mathrm{PaO}_{2}$, systemic oxygen delivery improved as a result of increased cardiac output during administration of iNO.
One limitation of this study was the use of an animal model to mimic acute pulmonary artery hypertension. Swine have been used in previous studies of cardiopulmonary interactions. ${ }^{9-11,25} \mathrm{Ad}$ ditionally, the cardiac and pulmonary anatomy and physiologic features of the swine are similar to those of human beings. This model does not examine the potential differences that can occur between newborn and older swine. Newborn swine may respond differently than older swine because of developmental differences. Examination of these developmental differences was not a subject of this investigation because we sought to characterize the response of older animals.

A second limitation of the study was the nonrandomized sequential delivery of NO. Measured differences between the iNO levels may be related to degradation of the preparation rather than real differences between the levels of iNO studied. After data collection at $80 \mathrm{ppm}$ of NO, delivery of NO was returned to $0 \mathrm{ppm}$. There were no significant differences between measurements made before inhalation of NO and those made after NO administration (Table II). These findings indicate that the measured differences were not a result of degradation of the preparation.

In summary, we have demonstrated that during global hypoxic pulmonary vasoconstriction, iNO improved pulmonary vascular mechanics by decreasing pulmonary artery pressure and input resistance through physiologic alterations in small vessels. Additionally, iNO improved RV performance by reducing RV total power requirements and improving transpulmonary vascular efficiency. These data suggest that iNO therapy is beneficial to the RV and should be considered in conditions with RV dysfunction and hypoxic pulmonary vasoconstriction. Further studies of iNO in conditions of RV dysfunction with and without hypoxic pulmonary vasoconstriction are warranted.

\section{REFERENCES}

1. Zapol WM, Snider MT. Pulmonary hypertension in severe acute respiratory failure. N Engl J Med 1977;296:476-80.

2. Radermacher P, Huet Y, Plusika F, et al. Comparison of ketanserin and sodium nitroprusside in patients with severe ARDS. Anesthesiology 1988;68:152-7.

3. Radermacher P, Santak B, Becker H, Falke KJ. Prostaglandin $E_{1}$ and nitroglycerin reduce pulmonary capillary pressure but worsen ventilation-perfusion distributions in patients with adult respiratory distress syndrome. Anesthesiology 1989;70:601-6.

4. Frostell C, Fratacci MD, Wain JC, Jones R, Zapol WM. Inhaled nitric oxide: a selective pulmonary vasodilator reversing hypoxic pulmonary vasoconstriction. Circulation 1991;83:2038-47. 
5. Frostell CG, Blomquist H, Hedenstierna $G$, Lundberg J, Zapol WM. Inhaled nitric oxide selectively reverses human hypoxic pulmonary vasoconstriction without causing systemic vasodilation. Anesthesiology 1993;78:427-35.

6. Roberts JD, Lang P, Bigatello LM, Vlahakes GJ, Zapol WM. Inhaled nitric oxide in congenital heart disease. Circulation 1993;87:447-53.

7. Wessel DL, Adaitia I, Giglia TM, Thompson JE, Kulik TJ. Use of nitric oxide and acetylcholine in the evaluation of pulmonary hypertension and endothelial function after cardiopulmonary bypass. Circulation 1993;88:2128-38.

8. Milnor WR. Hemodynamics. 2nd ed. Baltimore: Williams \& Wilkins, 1989:167-203.

9. Hillman ND, Black DR, Craig DM, et al. Transport efficiency is an indicator of increased right ventricular work in a lung injury model. Pediatr Res 1994;35(4 Pt 2):53A.

10. Hillman ND, Meliones JN, Black DR, Craig DM, Cheifetz IM, Smith PK. In acute lung injury, inhaled nitric oxide improves ventilation-perfusion matching, pulmonary vascular mechanics, and transpulmonary vascular efficiency. $\mathrm{J}$ Thorac Cardiovasc Surg 1995;110:593-600.

11. Cheifetz IM, Craig DM, Kern FH, et al. Nitric oxide improves transpulmonary vascular mechanics but does not change intrinsic right ventricular contractility in an acute respiratory distress syndrome model with permissive hypercapnia. Crit Care Med 1996;24:1551-61.

12. Loh E, Stamler JS, Hare JM, Loscalzo J, Colucci WS. Cardiovascular effects of inhaled nitric oxide in patients with left ventricular dysfunction. Circulation 1994;90:2780-5.

13. Sibbald WJ, Driedger AA, Myers ML, Short AI, Wells GA. Biventricular function in the adult respiratory distress syndrome. Chest 1983;84:126-34.

14. Hammon JW, Smith PK, McHale PA, Vanbinthuysen KM, Anderson RW. Analysis of pulsatile pulmonary blood flow in the unanesthetized dog. J Appl Physiol 1981;50:805-13.

15. McDonald DA. The relationship of pulsatile pressure to flow in arteries. J Physiol 1955;127:533-52.
16. Celermajer DS, Dollery C, Burch M, Deanfield JE. Role of endothelium in the maintenance of low pulmonary vascular tone in normal children. Circulation 1994;89:2041-4.

17. Bocchi EA, Bacal F, Auler JO, Carmone MJ, Bellotti G, Pileggi $F$. Inhaled nitric oxide leading to pulmonary edema in stable severe heart failure. Am J Cardiol 1994;74:70-2.

18. Semigran MJ, Cockrill BA, Kacmarek R, et al. Hemodynamic effects of inhaled nitric oxide in heart failure. J Am Coll Cardiol 1994;24:982-8.

19. Bigatello L, Hurford WE, Kacmarek RM, Roberts JD Jr, Zapol WM. Prolonged inhalation of low concentrations of nitric oxide in patients with severe adult respiratory distress syndrome: effects on pulmonary hemodynamics and oxygenation. Anesthesiology 1994;80:761-70.

20. Puybasset L, Stewart T, Rouby JJ, et al. Inhaled nitric oxide reverses the increase in pulmonary vascular resistance induced by permissive hypercapnia in patients with acute respiratory distress syndrome. Anesthesiology 1994;80:125467.

21. Puybasset L, Rouby JJ, Mourgeon E, et al. Inhaled nitric oxide in acute respiratory failure: dose-response curves. Intensive Care Med 1994;20:319-27.

22. Miller OI, Celermajer DS, Deanfield JE, Macrae DJ. Verylow-dose inhaled nitric oxide: a selective pulmonary vasodilator after operations for congenital heart disease. J Thorac Cardiovasc Surg 1994;108:487-94.

23. Journois D, Pouard P, Mauriat P, Malhere T, Vouhe P, Safran D. Inhaled nitric oxide as a therapy for pulmonary hypertension after operations for congenital heart disease. J Thorac Cardiovasc Surg 1994;107:1129-35.

24. Beghetti M, Habre W, Friedli B, Berner M. Continuous low dose inhaled nitric oxide for treatment of severe pulmonary hypertension after cardiac surgery in paediatric patients. $\mathrm{Br}$ Heart J 1995;73:65-8.

25. Jacob TD, Nakayama DK, Seki I, et al. Hemodynamic effects and metabolic fate of inhaled nitric oxide in hypoxic piglets. J Appl Physiol 1994;76:1794-801. 